\title{
The Discrete Multicriteria Decision Methods And ARSV Model Used To Choice The Best Exchange Rate
}

María del Carmen García-Centeno, Ph.D., University San Pablo CEU, Spain Román Mínguez Salido, Ph.D., University of Castilla-La Mancha, Spain

\begin{abstract}
The exchange rate is a variable that economic agents have in consideration. For this reason, in this paper we suggest a decision method to compare several exchange rates. This method is the Promethee Method and it is a Multicriteria Decision Method used to order the preference between returns of the different exchange rates. We have used different statistic criteria to rank these exchange rates. To obtain the pay-off matrix it has been used one econometric model: Autoregressive Stochastic Volatility (ARSV) Model. We have proposed different generalized criteria and their corresponding thresholds. Both are used to evaluate the different exchange rate returns in the decision matrix or the pay-off matrix. These thresholds are suggested according to the obtained results in the decision matrix. Finally, we have obtained the best solution of the problem when all the criteria have the same importance for the decision-maker.
\end{abstract}

Keywords: Exchange rate, ARSV model, Stochastic volatility; Discrete Multicriteria Methods

\section{INTRODUCTION}

¿ $\mathrm{n}$ the specialized literature a lot of empirical work is available trying to explain the determinants of exchange rates. Nevertheless, in our knowledge, there has not been any study which ranks with multicriteria methods the exchange rates using statistical and econometrical information. In this methodology, the first step is to summary the statistical evidence using the usual descriptive statistics and to estimate the non-observable volatility through econometric ARSV model. Afterwards, this information is gathered using partial and complete preference orders which allow the decision-maker to get an ordered ranking of the different exchange rates.

The remainder of the paper is organized as follows: Section 2 shows methodology and the objectives. Section 3 the empirical finding and finally, section 4 provides some concluding remarks.

\section{STUDY METHODOLOGY AND OBJECTIVES}

The methodology is based in the analysis of the stylized facts of the returns and to explain its dynamic with the ARSV model. Then, the objective of this paper is to obtain the preference order between the different returns in analysed sample period.

The stylised facts are important as they will be used as criteria in the decision matrix of the program set out in the form of discrete multicriteria decision. The returns $\left(y_{t}\right)$ are calculated as follow:

$y_{t}=100\left(\log X_{t}-\log X_{t-1}\right)$

where $X_{t}$ is the exchange rate value at time t. 
Taking into account that all the daily exchange rate returns have the same main characteristics, in this section we will only use the Dollar to Euro exchange rate $^{1}$ as an example to explain the characteristics of the daily financial returns series.

The daily financial returns series have the following main stylised facts:

1) The returns fluctuate around a constant small level close to zero, Figure 1(b).

2) The conditional variance is not constant due to periods with a large variability (which coincide with periods in which the variation of Dollar to Euro exchange rate returns are bigger, Figure 1(a)) following the other periods with a small variability (which coincide with periods in which the exchange rate returns do not have high variation, Figure 1(a)). This stylized fact is known as volatility clusters, Figure 1(b).

3) The autocorrelation function of returns, Figure 1(c), shows that the returns are uncorrelated but they are not independent because the autocorrelation function of square returns, Figure 1(d), due to the existence of volatility clusters, shows a dependence structure which is shown by significant correlations. In the majority of time series, these correlations are positive and they decrease slowly to zero; this is known as volatility persistence.

4) The returns do not have a Normal distribution because they have a negative or positive skewness and kurtosis excess, Figures 1(e) y 1(f) and Table 1.

Figure 1. Dollar to Euro Exchange rate from 4/1/1999 to 5/11/2010
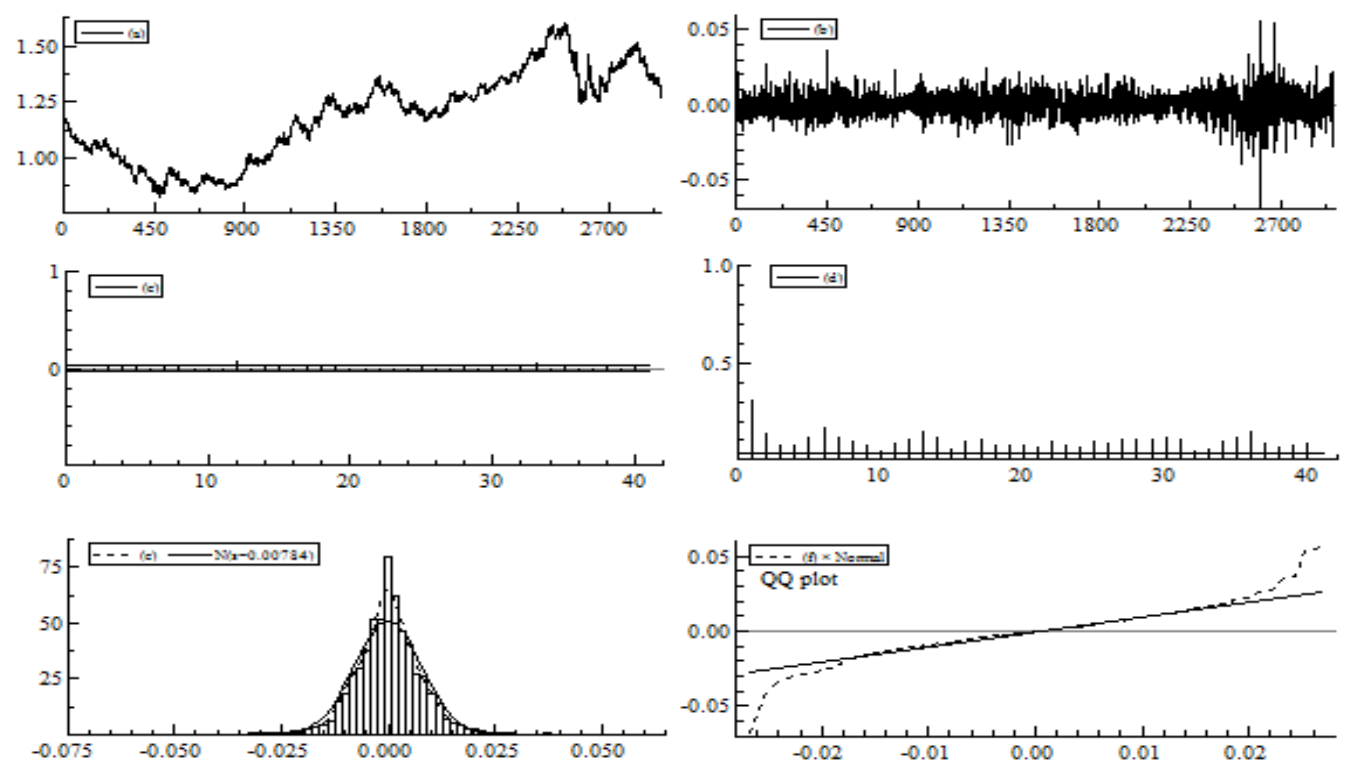

(a): Time plot of Dollar to Euro exchange rate; (b): Dollar to Euro exchange rate returns; (c): Correlogram (or autocorrelation function, ACF) of Dollar to Euro exchange rate returns. 5\% significance level; (d): ACF of Dollar to Euro exchange rate returns. 5\% significance level; (e): Histogram and estimated density plot of Dollar to Euro exchange rate returns. 5\% significance level. (f) QQ plot for FTSE Dollar to Euro exchange rate returns.

\footnotetext{
${ }^{1}$ The data for all exchange rates used in this paper have been obtained from the DataStream Data Base.
} 
Table 1. Descriptive Statistics and Normality test for several Exchange Rates Sample period from $4 / 1 / 1999$ to $11 / 05 / 2010$

\begin{tabular}{|l|c|c|c|c|c|c|c|}
\hline \multicolumn{1}{|c|}{ Exchange Rates } & Minimum & Maximum & Mean & $\begin{array}{c}\text { Std. } \\
\text { Devn. }\end{array}$ & Skewness & $\begin{array}{c}\text { Excess } \\
\text { Kurtosis }\end{array}$ & $\begin{array}{c}\text { Normality } \\
\text { Test }\end{array}$ \\
\hline US To Euro & -0.0676 & 0.0557 & 0.00003 & 0.0070 & -0.0242 & 4.8175 & $1151.4^{*}$ \\
\hline Japanese Yen To Euro & -7.01 & 5.03 & -0.0005 & 1.0131 & -0.4144 & 3.6489 & $648.21^{*}$ \\
\hline UK To Euro & -0.0252 & 0.0323 & 0.00005 & 0.0038 & 0.63815 & 8.4847 & $1959.3^{*}$ \\
\hline Swiss Franc To Euro & -0.0362 & 0.0453 & 0.016 & 1.1250 & -0.0698 & 10.317 & $3120.5^{*}$ \\
\hline Swedish Krona To Euro & -0.2510 & 0.2970 & 0.00006 & 0.0401 & 0.2599 & 6.1908 & $1550.6^{*}$ \\
\hline Norwegian Krone To Euro & -0.3550 & 0.3500 & -0.0003 & 0.0363 & 0.1305 & 12.010 & $3735.4^{*}$ \\
\hline
\end{tabular}

*It is significant at 5\% significance level. The Normality test used is the Jarque-Bera test $\left(\mathrm{H}_{0}\right.$ is a Normal distribution). The mean is statistically zero for all exchange rates.

These stylised facts show that volatility has some regularities in its behaviour and it is possible to propose the ARSV model for modelling the dynamics of volatility, Teräsvirta and Zhao, 2006. Also, the volatility and its behaviour throughout time is a very relevant element within the characteristics of this type of financial time series. However, volatility is a non-observable variable and it is necessary to propose an econometric model to estimate it, such us, ARSV model introduced by Taylor, 1986.

\subsection{The ARSV model}

The process proposed to describe the dynamics of volatility is an $\operatorname{ARSV(1),~which~is~defined~by~the~}$ following equations:

- The mean equation: $\quad y_{t}=\sigma_{*} \exp \left(0.5 h_{t}\right) \varepsilon_{t} \quad \varepsilon_{t} \sim$ i.i.d $N(0,1)$

- The log-volatility equation: $h_{t}=\phi h_{t-1}+\eta_{t} \quad \eta_{t} \sim$ i.i.d. $N\left(0, \sigma_{\eta}^{2}\right)$

where, $\mathrm{y}_{\mathrm{t}}$ are the returns; $\sigma_{*}$ is a positive scale factor in the mean equation to avoid including a constant in the logvolatility equation; $\varepsilon_{\mathrm{t}}$ is a random disturbance (white noise) in the mean equation and it follows a Normal distribution with mean zero and variance one; $\sigma_{t}^{2}$ is the volatility and it is modelled as an exponential function to guarantee it is positive; $\mathrm{h}_{\mathrm{t}}$ is the $\log$-volatility, $h_{t}=\log \sigma_{t}^{2} ; \eta_{\mathrm{t}}$ is a white noise process in the log-volatility equation and it follows a Normal distribution with mean zero and variance $\sigma_{\eta}^{2}$; the distribution of $\varepsilon_{t}$ and $\eta_{t}$ are independent, $E\left(\varepsilon_{t} \eta_{t}\right)=0, \forall \mathrm{t}, \mathrm{s}$

The estimation ${ }^{2}$ method for the ARSV model was developed by Doornik, 2000 and it is implemented in the Ox programming language with the package named SsfPack 2.2, see Koopman et al., 1999, Koopman and Uspensky, 2002. After obtaining the estimated values of the unobserved volatility with this model, we establish a preference order between the different exchange rates using the PROMETHEE methods.

\subsection{Promethee Methods}

The PROMETHEE is a multicriteria decision aid method, see Brans et al., 1984, Brans and Wincke, 1985, Goumans and Lygerou, 2000, based on the comparison between preference functions. In these methods the preference function translates the deviation between the evaluations of two actions on a single criterion in terms of a preference degree. The preference degree is an increasing function of the deviation: smaller deviations will contribute to weaker degrees of preferences and larger ones to stronger degrees of preferences. To facilitate the association of a preference function to each criterion, the literature has proposed the following six specific shapes:

\footnotetext{
2 The estimation program for the ARSV(1) model has been developed in Ox programming and it can be downloaded for free at www.feweb.vv.nl/koopman/sv
} 


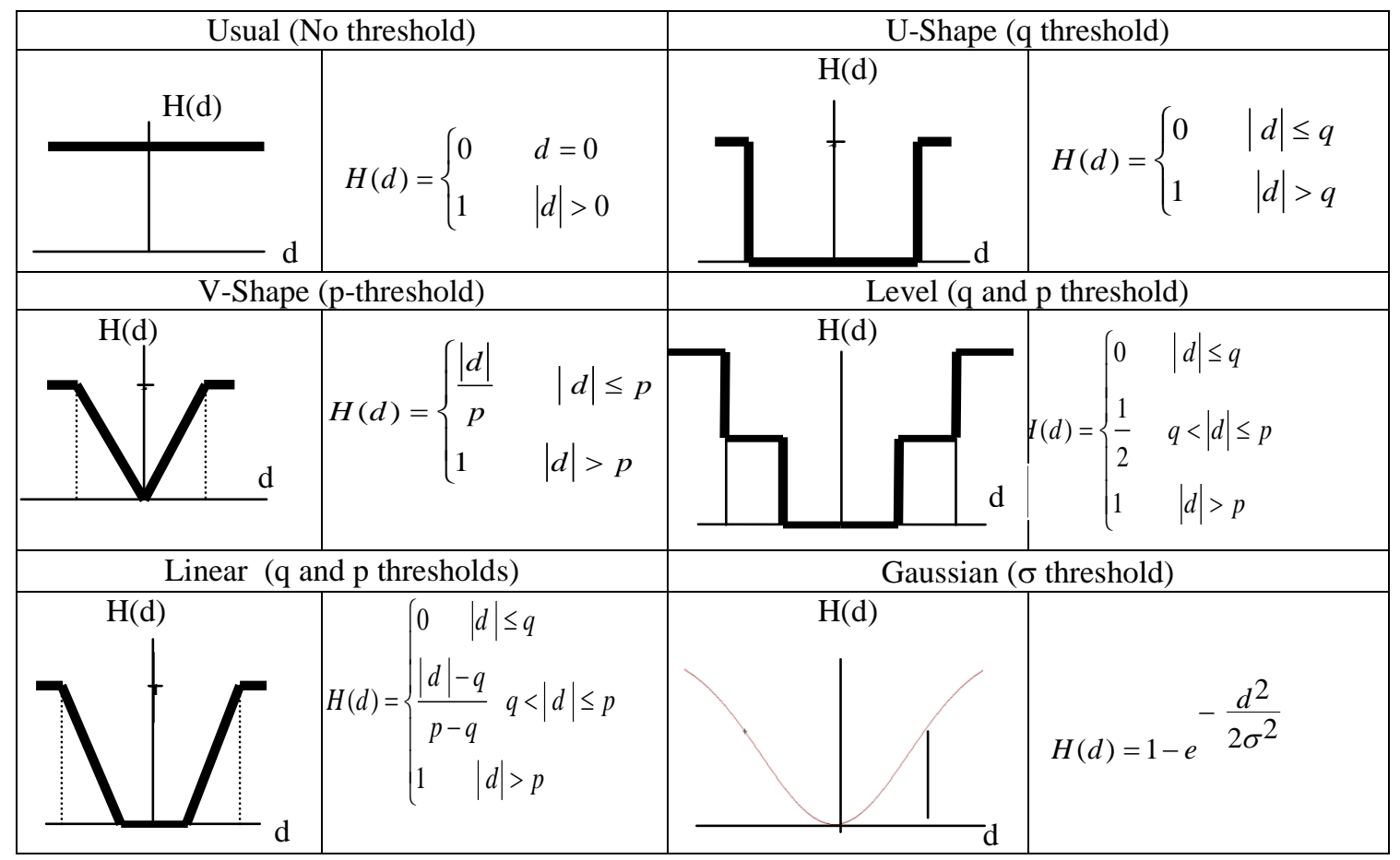

The indifference threshold q represents the largest deviation that is considered negligible by the decisionmaker. The preference threshold $\mathrm{p}$ represents the smallest deviation that is considered as decisive by the decisionmaker ( $p$ cannot be smaller than q). The Gaussian threshold $\sigma$ is a middle value that is only used with the Gaussian preference function.

All information about the problem is summarized in the pay-off matrix. The preference indexes matrix is obtained from the pay-off matrix comparing systematically one to one each action with the others. The preference indexes are calculated as following:

$I\left(a_{i}, a_{j}\right)=\sum_{i} w_{i} H_{i}(d)$

where, $a_{i}, a_{j}$ represent two different actions; $w_{i}$ are the normalized weights of each criterion; and, $H_{i}(d)$ is the corresponding result for each preference function.

The PROMETHEE I partial ranking is defined as the simultaneous comparisons of the positive flows $\left(\phi^{+}\right)$ and negative flows $\left(\phi^{-}\right)$rankings. When there is a conflict between the positive and negative flows, the actions are considered incomparable in the PROMETHEE I ranking and it is necessary to use PROMETHEE II to solve the conflict using the net flow $(\phi)$. These net flows are calculated as following:

$\phi=\phi^{+}-\phi^{-}$

\section{EMPIRICAL FINDINGS}

The data analyzed in this section corresponds to six daily exchange rate returns: US to Euro, Japanese Yen to Euro, UK to Euro, Swiss Franc to Euro, Swedish Krona to Euro, Norwegian Krone to Euro. Table 1 summarizes some information about these exchange rates and their returns in the sample period from 4/1/1999 to 11/05/2010. This section examines two aspects: 
- $\quad$ The ability of ARSV model to explain the dynamics of volatility and the rest of stylized facts for several exchange rates returns; and,

- $\quad$ The preference order between these returns using the PROMETHEE methods and all the statistical information previously summarized.

\subsection{Estimated results of ARSV model}

The available statistical information of the exchange rates returns analyzed in this paper shows that their mean is constant and close to zero. US/Euro, Yen/Euro and Swiss Franc/Euro present negative asymmetry and the rest it is positive, Table 2. Also, there is an excess of kurtosis due to, among other facts, the existence of outliers. On the other hand, since it is essential to have as much information as possible so as to choose the best possible alternative, we will also include volatility in our analysis.

The persistence of volatility is estimated by the $\phi$ parameter in the ARSV(1) model and it is higher and close to one, see Table 2.

Table 2. Evaluation for Scenario II (including estimation of ARSV(1) model

\begin{tabular}{|l|c|c|c|c|c|c|c|}
\multicolumn{1}{c|}{} & $\begin{array}{c}\text { Mean } \\
\text { Returns }\end{array}$ & $\begin{array}{c}\text { STD } \\
\text { Returns }\end{array}$ & $\begin{array}{c}\text { Mean } \\
\text { Volatility }\end{array}$ & $\begin{array}{c}\text { STD } \\
\text { Volatility }\end{array}$ & Skewness & Persistence & Kurtosis \\
\hline US to Euro & 0.00003 & 0.0070 & 0.0073 & 0.0023 & -0.0242 & 0.9946 & 4.8175 \\
\hline Japanese yen to Euro & -0.0005 & 1.0131 & 0.9090 & 0.3538 & -0.4144 & 0.9891 & 3.6489 \\
\hline UK to Euro & 0.00005 & 0.0038 & 0.0032 & 0.0017 & 0.63815 & 0.9979 & 8.4847 \\
\hline Swiss Franc to Euro & 0.016 & 1.1250 & 0.0036 & 0.0019 & -0.0698 & 0.9992 & 10.317 \\
\hline Swedish Krona to Euro & 0.00006 & 0.0401 & 0.0338 & 0.019 & 0.2599 & 0.9919 & 6.1908 \\
\hline Norwegian Krone to Euro & -0.0003 & 0.0363 & 0.0312 & 0.0144 & 0.1305 & 0.9755 & 12.010 \\
\hline Function Type & V-Shape & Usual & V-Shape & Usual & Linear & Usual & Usual \\
\hline Minimized & False & True & False & True & True & False & True \\
\hline p & 0.0002 & - & 0.1 & - & 1 & - & - \\
\hline q & - & - & - & - & 0.05 & - & - \\
\hline Weights & 1 & 1 & 1 & 1 & 1 & 1 & 1 \\
\hline
\end{tabular}

Once we have analyzed the main results from ARSV model, we will proceed to establish an order of preference among the results using PROMETHEE methods.

\subsection{Order of Preferences between daily financial returns}

We use the PROMETHEE methods to establish a preference order between the daily exchange rate returns: US to Euro, Japanese Yen to Euro, UK to Euro, Swiss Franc to Euro, Swedish Krona to Euro, Norwegian Krone to Euro. These returns are evaluated by several criteria, some of them based on the descriptive statistics of the returns and others based on the estimated volatility with ARSV model. The main criteria, related to the descriptive statistical information gathered, are the following: the mean, the standard error (STD), the skewness and the kurtosis of the returns, the mean and the standard error of the estimated volatility and the persistence estimated of the volatility with ARSV model. The criteria maximized are mean returns, mean volatility and persistence, the rest of the criteria are minimized.

The criteria have the same importance and, therefore, all the weights are the same (in this case we suppose they are equal to one), Figueira and Roy, 2002. Every criterion is evaluated by the most adequate generalized criteria (function types). We have assigned their corresponding thresholds in accordance with the evaluations of each action; see Table 2 for the pay-off matrix.

The partial ranking shown with PROMETHEE I is based on strongly established preferences. As a consequence, not all financial returns of the different exchange rate can be compared one to one with the others. For scenario I, see Figure 2 where UK/Euro is incomparable with US/Euro and Swiss Franc is incomparable with 
Yen/Euro. The ranking of preference is represented graphically (arrows denote preferences), so that, for instance, the best exchange rates are UK/Euro and US/Euro; the worst is Krone/Euro, see Figure 2.

Figure 2 Partial Ranking (PROMETHEE I) for ARSV(1) model with equal weights

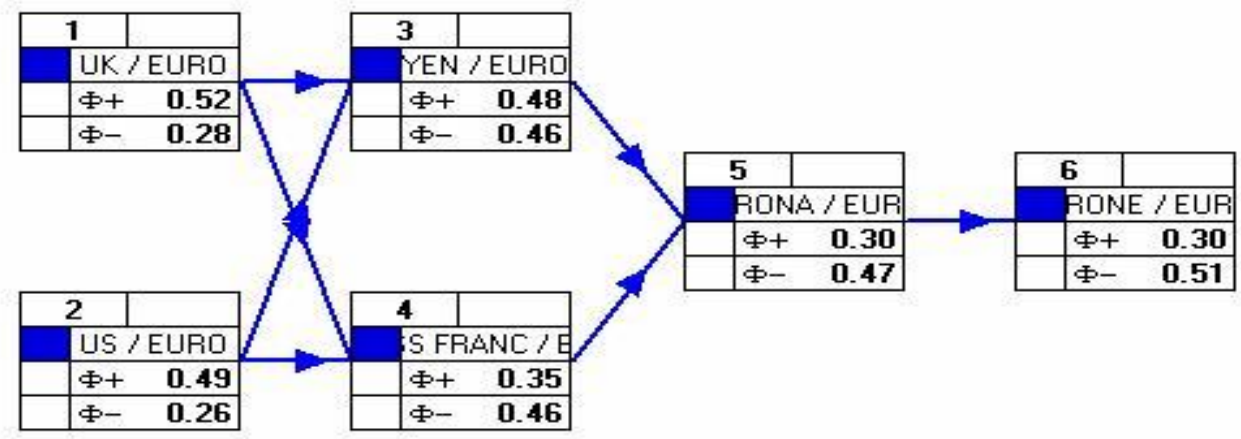

The complete ranking (PROMETHEE II) indicates that all exchange rates returns are ranked from best to worst, leaving no incomparability of actions. In this case we can assert that preference order between exchange rate returns are the following: UK/Euro, US/Euro, Yen/Euro, Swiss Franc/Euro, Krona/Euro, Krone/Euro, see Figure 3.

Figure 3. Complete Ranking (PROMETHEE II) for Scenario II with equal weights

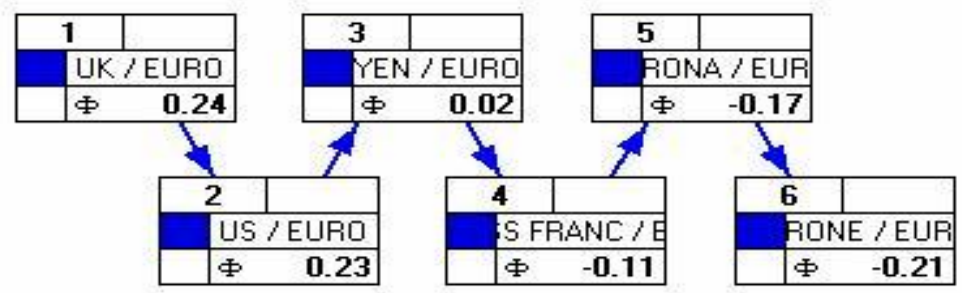

\section{CONCLUSIONS}

The sample variation of exchange rates shows the same stylized facts that they are usually found in the majority of high-frequency financial series. This fact justifies the use of an econometric model in this work to estimate the dynamic of conditional volatility in exchange rates. We have analyzed the results coming from ARSV model, this model is better than others because it has a better behaviour specially when there are high volatility clusters. The statistical and econometrical information available will allow us to establish a preference order among the different exchange rates.

Then, this study focused on establishing a preference order between different exchange rates. To obtain this preference order we propose to use ARSV(1) model to obtain an adequate estimations of the volatility and to used these estimations to obtain some criteria to evaluate the exchange rates.

First, we have built partial orders and the results show that the best exchange rate are UK to Euro and US to Euro and the worst one is Norwegian Krone to Euro. However, there are some incomparabilities between some exchange rates. To overcome this incomparability, we have built a complete order based on the net flow. The results are quite robust, in fact the best and worst exchange rates coincide with the previous case. 


\section{AUTHOR INFORMATION}

María del Carmen García-Centeno: $\mathrm{PhD}$ in Economics by University CEU San Pablo and Degree in Economic and Business Administration by Complutense, Madrid (Spain). Assistant Professor in Econometric at Statistics Department. Faculty of Economics and Business Administration, University CEU San Pablo (Spain). Email:garcen@ceu.es.

Research Interest: Stochastic volatility models, regional analysis, educational and tourism.

Román Mínguez-Salido: PhD in Economics by University CEU San Pablo and Degree in Economic and Business Administration by Complutense, Madrid (Spain). Assistant Professor in Statistics at Statistics Department. Faculty of Social Sciences of Cuenca. University of Castilla-La Mancha (Spain). E-mail: Roman.Minguez@uclm.es.

Research Interest: Stochastic volatility models, regional analysis, educational and tourism.

\section{REFERENCES}

1. Brans, J.P., Mareschal, B. and Vincke, P.H. (1984). "PROMETHEE: a new family of outranking methods in multicriteria analysis", in J.P BRANS (ed.), Operational Research'84, North-Holland, pp. 477-490.

2. Brans, J.P. and Vincke, P.H. (1985). "A preference ranking organization method, the PROMETHEE method" Management Science, vol. 31, pp. 647-656.

3. Doornik, J.A. (2001). “An object-oriented matrix programming language using Ox". Timberlake Consultants Ltd., http://timberlake.co.uk.

4. Figueira, J. and Roy, B. (2002). "Determining the weights of criteria in the ELECTRE type methods with a revised Simos1' procedure". European Journal of Operational Research, vol. 139, pp. 317-326.

5. Goumans, M. and Lygerou, V. (2000). "An extension of the PROMETHEE method for decision making in fuzzy environment: Ranking of alternative energy exploitation projects". European Journal of Operational Research, vol. 123, n $\mathrm{n}^{\mathrm{O}}$ 3, pp. 606-613.

6. Koopman, S.J.; Shephard, N. and Doornik, J.A. (1999). "Statistical algorithms for models in state space using SsfPack 2.2", Econometrics Journal, vol. 2, pp. 1-55.

7. Koopman, S.J. and Hol Uspensky, E.A. (2002). "The Stochastic Volatility in Mean Model: Empirical evidence from international stock markets", Journal of Applied Econometrics. Vol. 17, no 6, pp. 667-689.

8. Teräsvirta, T. and Zhao, Z. (2006). "Stylized facts of return series robust estimates and three popular models of volatility." Unpublished working paper, Stockholm School of Economics.

9. Taylor, S.J. (1986). Modeling Financial Time Series. John Wiley and Sons Ltd, New York. 
NOTES 